\title{
AVALIAÇÃO SISTEMÁTICA DE ALTERAÇÕES NO PROJETO DE UMA TRITURADORA DE VIDRO
}

\author{
João Gabriel da Cruz Passos ${ }^{1}$ (joaoglancetti), Mariana dos Santos Barroso ${ }^{1}$ \\ (marianabarroso308@gmail.com), Ana Flávia de Oliveira Alencar ${ }^{1}$ (flavinhagherardi), Leandro Reis \\ Muniz² (leandro.reis@ufsj.edu.br), Artur Mariano de Sousa Malafaia ${ }^{2}$ (arturmalafaia@ufsj.edu.br )
}

(1) Universidade Federal de São João del-Rei (UFSJ), Curso de Engenharia Mecânica, Praça Frei Orlando170, Centro, 36307-904, São João del-Rei, Minas Gerais, Brasil.

(2) Universidade Federal de São João del-Rei (UFSJ), Departamento de Engenharia Mecânica, Praça Frei Orlando-170, Centro, 36307-904, São João del-Rei, Minas Gerais, Brasil.

RESUMO: Devido a boa demanda no município de São João del Rei, Minas Gerais, e, buscando auxiliar a Associação de Catadores de Material Reciclável da cidade como uma nova fonte de renda, foi proposto um projeto de uma moedora de vidro desenvolvida com base em técnicas de projetos de produtos e tecnologias sociais desenvolvidas por alunos e professores do curso de Engenharia Mecânica da Universidade Federal de São João del-Rei. Permitindo assim, que um equipamento simples, ajude a gerenciar os resíduos de vidro, transformando-os em pequenos cacos com total segurança e eficácia. Para a criação de um equipamento confiável, ambientalmente correto, economicamente viável, e fácil manutenção, é indispensável a determinação correta das condições de trabalho nas quais a máquina está sujeita bem como, seu dimensionamento adequado. O projeto da máquina foi baseado em mecanismos simples, com o princípio de funcionamento baseado no impacto dos martelos com o material a ser moído, comum em moinhos de martelo. Juntamente com sua construção ocorreram alterações no escopo do projeto original devido ao surgimento de alguns obstáculos. As alterações apresentaram características satisfatórias nos testes em relação aos objetivos estabelecidos originalmente e capacidade de solucionar os problemas encontrados. Logo, o presente trabalho visa avaliar a máquina como um todo, sintetizando as alterações na forma de uma comparação do projeto original com o projeto atual, além de definir quais são as influências das decisões não previstas tomadas na construção da mesma.

PALAVRAS-CHAVE: projeto mecânico, moinho de martelos, vidro, reciclagem, catadores. (deixar duas linhas em branco - Times New Roman, tamanho 11)

\section{INTRODUÇÃO}

Com o objetivo de aplicar conhecimentos de engenharia no desenvolvimento positivo da situação socioambiental na cidade, alunos da Universidade Federal de São João del-Rei desenvolveram uma máquina trituradora de vidros (Passos et al., 2018). Entretanto, foram necessárias alterações no projeto teórico durante a fabricação do equipamento.

A ideia da máquina foi permitir o processamento de vidro aos catadores da Associação de Catadores de São João del-Rei (ASCAS), constituída em 2003. Ainda em 2002 foi feita uma aproximação entre os catadores e a universidade, na forma do projeto multidisciplinar de nome "Inclusão Social dos Catadores de Material Reciclável de São João del-Rei e conscientização ambiental”. Este projeto, assim como as diversas 

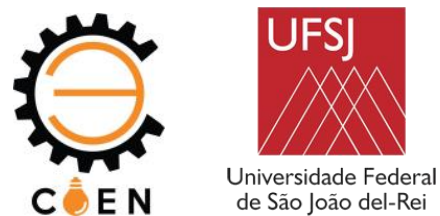

facetas da parceria entre a universidade e a ASCAS, é garantir aos membros da associação uma forma de sustento econômico com a participação em um grupo autogerido. (Abreu e Barbosa, 2007)

Sem o equipamento, os catadores eram incapazes de processar o vidro, embora a reciclagem do mesmo seja economicamente viável e possua um impacto positivo no meio ambiente, retirando-o da natureza e economizando energia na produção de novos produtos. (ABIVIDRO, 2019) Em números descritos por MEDINA, o processo representa uma redução de uso de energia em até 32\%, $20 \%$ da poluição do ar, $80 \%$ de resíduos de mineração e $50 \%$ no uso de água.

A moagem do vidro é necessária para torna-lo mais compacto, facilitando seu transporte. Para este fim, o uso de trituradores não é inédito, sendo encontrados projetos como o de Ferrari et al. (2018). Além de considerar os limites impostos pelos recursos disponíveis, o projeto da máquina exige uma certa flexibilidade, para se adaptar às necessidades dos clientes. (FILHO et al., 2011)

A diferença entre um projeto teórico e prático é esperada, devido aos fatores comentados. Por isso, autores como Norton apresentam até mesmo processos iterativos de projeto. Estes processos admitem a presença de obstáculos de natureza variada no decorrer do processo, e preveem o retorno a fases anteriores do mesmo, alterando-o em comparação ao desígnio original. Há sempre o espaço para melhoras no projeto, segundo o autor, e as iterações podem continuar indefinidamente. Porém isso exigiria tempo e recursos, logo, é interessante que todas as fases do projeto sejam bem conduzidas, reduzindo o trabalho necessário para se chegar do projeto inicial à versão final.

No caso de trituradores, existem diversos modelos com variados mecanismos de moagem. Eles são utilizados, por exemplo na preparação de pós cerâmicos para a consolidação. Rahaman, por exemplo, menciona moinhos de bolas, de jatos e de rolos. O projeto optou pelo desenvolvimento de um moinho de martelos. A opção foi tomada devido a maior facilidade de construção dos mesmos, sendo encontrados até mesmo trabalhos como o de Andrade e Chiriboga. (2018), também focado no desenvolvimento de um moinho de martelos por estudantes de Engenharia Mecânica.

Mesmo sendo mecanismos mais simples, e o princípio de funcionamento baseado no impacto em alta velocidade dos chamados martelos com o material a ser cominuído seja mantido, existem vários fatores a se considerar no projeto de um triturador deste modelo (MICHAUD, 2019). O espaço vazio na região de moagem (não ocupado por martelos, por onde flui o material), por exemplo, é um ponto de discussão levantado em trabalhos há bastante tempo, como em Friedrich (1959).

Como o choque que leva à quebra do material normalmente ocorre entre o mesmo e a ponta dos martelos e as paredes da máquina (Jindal e Augustin), o espaço ali presente é um fator de interesse também, podendo influenciar em até $400 \%$ na eficiência de moagem (YANCEY, WRIGHT \& WESTOVER. 2013). O formato e localização da peneira, caso exista, também são fatores importantes, como menciona Koch (2002).

Logo, não há um modelo definitivo no qual se espelhar, cada um sendo dotado de seus pontos superiores e inferiores na comparação com outros. Por isso, os responsáveis não se ataram ao projeto original, e com o surgimento de certos obstáculos no desenvolvimento do mesmo, alterações foram pensadas de modo a não impactar negativamente a máquina, mas ainda oferecer uma solução ao problema encontrado, baseando-se no processo de projeto descrito por Shigley, e um aparelho capaz de corresponder às demandas foi produzido.

Todavia, julgou-se adequado, ao fim do processo, avaliar de forma isolada cada conjunto funcional da máquina, com o intuito de sintetizar as alterações na forma de uma comparação com o projeto original. A intenção final é definir quais são as influências das decisões não previstas tomadas na construção da máquina por uma análise do aparelho como um todo.

\section{MATERIAIS E MÉTODOS}



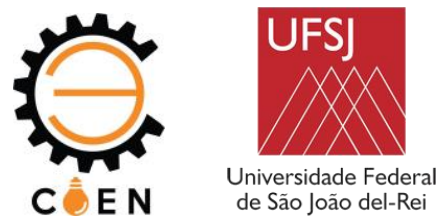

Para que a avaliação das alterações pudesse ser feita, julgou-se adequado dividir a máquina em conjuntos funcionais. Tais conjuntos procuram subdividir o aparelho em partes, sendo cada parte responsável de forma geral por uma das etapas de moagem e pela integridade da estrutura. Foram definidas três divisões, a entrada, o conjunto de moagem e a base.

Quando se julgou adequado, foram feitos comentários quanto ao custo, porém este não foi tipo como um fator, primário. Tal decisão foi guiada pela dificuldade em estimá-lo, permitindo apenas comparações superficiais.

\subsection{Entrada}

A entrada consiste no caminho a ser percorrido pelo material até seu choque com os martelos. Sendo assim, sua função é dada como cumprida quando determinado objeto, ao ser colocado em um ponto qualquer definido como a entrada da máquina, é levado sem qualquer outra interação com o operador à câmara de moagem.

Além de estabelecer tal conexão, a entrada deve garantir a segurança do operador e demais pessoas próximas do equipamento durante a moagem. Os riscos de segurança neste processo se referem principalmente a possibilidade de que, após o choque com os martelos, particulados de vidro retornem pelo canal de alimentação. Logo, deve ser um caminho completamente fechado. Além disso, a região na qual o material é inserido deve ser projetada de modo a permitir a entrada do mesmo, porém impedir sua saída.

Quanto à integridade da estrutura, é importante considerar o efeito do projeto do canal de entrada em relação ao peso da máquina, os esforços desenvolvidos na estrutura, o processo utilizado para conectar a entrada à câmara de moagem e a instabilidade induzida pelo mesmo. Todos estes fatores estão relacionados principalmente ao peso do acessório, buscando-se sempre a redução do mesmo.

Outro fator de interesse é o centro de gravidade (CG) do canal. Um centro de gravidade mais distante horizontalmente do centro da mesa causa maiores esforços e induz instabilidade. A distância vertical do centro ao solo, por sua vez, pode levar a uma elevação considerável do centro de gravidade da estrutura, também induzindo instabilidade. Porém este fator é secundário ao peso, pois um peso pequeno ameniza o efeito da localização do CG, e torna o equipamento como um todo mais fácil de ser transportado.

\subsection{Conjunto de moagem}

O conjunto de moagem abrange a câmara onde o vidro é triturado, o eixo com os martelos o sistema de acionamento e o sistema de controle da granulometria do material. Nesta região, é essencial que o vidro alimentado seja reduzido até a dimensão desejada. Para tanto, é importante principalmente definir uma geometria interna da câmara e disposição dos martelos que permitam a quebra do material.

O sistema de acionamento tem influência principalmente na taxa máxima de alimentação do equipamento, pois é sua reponsabilidade fornecer torque ao eixo. A vibração induzida pelo mesmo e pelo processo de moagem deve ser mantida a um nível controlável, evitando causar danos ao sistema.

Todos os elementos de acoplamento entre os martelos e o eixo, e o motor e o eixo, assim como os rolamentos, precisam resistir ao regime de trabalho e transmitir torque com uma boa eficiência. $\mathrm{O}$ peso do sistema como um todo deve ser considerado, porém nesta região não há tanto espaço para otimização nesse quesito.

O controle da granulometria, a ser feito por um elemento como uma peneira, é projetado de modo a manter as partículas maiores de vidro dentro da câmara por tempo o bastante para que novos choques com os martelos as tornem pequenas o bastante. $\mathrm{O}$ tamanho desejado deve ser estipulado pelas necessidades dos clientes. 

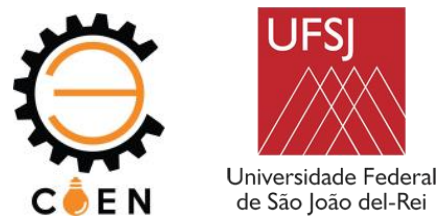

Esse é o sistema mais importante da máquina, responsável por seu funcionamento. Porém exatamente por este motivo a análise dedicada ao mesmo foi mais simples. É importante apenas que seja entregue potência o bastante para realizar a cominuição do vidro e entregue o particulado no tamanho desejado. Considerações quanto a peso, segurança, estabilidade e outros quesitos verificados são responsáveis principalmente para garantir a ausência de qualquer problema grave, e não são guiados por uma busca por otimização.

\subsection{Base}

A base da máquina comprime todos os elementos responsáveis pela conexão da mesma ao solo. Sua função é sustentar o sistema e moagem e a entrada do equipamento, garantindo espaço suficiente para a saída do vidro moído.

Neste sistema, é possível controlar também a altura máxima da máquina. Junto ao modo de alimentação, a altura tem papel importante na ergonomia dos operadores, e deve ser sempre considerada tendo em vista a altura média destes. Em contrapartida, a redução da altura da base é limitada pelo espaço a ser deixado na parte inferior da máquina, que deve acomodar o recipiente de armazenamento do vidro moído.

Também na saída, é importante criar um canal vedado. A função deste canal é conectar o fluxo de material na saída com o recipiente de armazenamento sem permitir o contato deste com o ambiente externo. Isso impede que partículas sejam expelidas para fora do recipiente em alta velocidade, um risco de segurança. Além disso, evita acúmulo de vidro no chão, tornando o processo mais limpo e, devido à natureza cortante do vidro, também mais seguro.

A base ainda deve ser estável e rígida, pois nela se sustenta todo o peso do equipamento, e o tombamento tem princípio na mesma. Ainda é importante garantir que haja uma forma de transportar a máquina facilmente, e tal consideração é mais bem aplicada no projeto da base.

Os três conjuntos abrangem todos os elementos da mesma, e uma avaliação, partindo dos pontos de interesse levantados, e comparando o projeto inicial com o final, foi realizada de modo a analisar as diferenças entre o estado inicial e final do projeto. Os resultados e as discussões decorrentes foram desenvolvidos a partir dos recursos julgados necessários para fazê-lo, tendo como base as considerações do método.

\section{RESULTADOS E DISCUSSÕES}

\subsection{Entrada}

O projeto original da entrada seria um dispositivo semelhante a uma calha, de grandes dimensões, construído em chapas de 7,5 mm de espessura. O mesmo permitiria uma alimentação adequada a grande potência do sistema de moagem, por permitir que várias garrafas fossem inseridas em uma pequena quantidade de tempo. Porém as dimensões elevadas tornam o processo de construção e fixação complicados, além de comprometer a integridade e estabilidade estrutural.

$\mathrm{O}$ projeto original da entrada está representado na Figura 1 a. $\mathrm{O}$ componente possui um peso de aproximadamente $70 \mathrm{~kg}$, e sua massa está distribuída ao longo de um grande comprimento, portanto seu centro de massa se encontra mais afastado do ponto de apoio do equipamento. Seu peso excessivo ainda exigiria uma barra de apoio ligando o centro de massa da calha à mesa. Por outro lado, sua entrada maior possui uma largura de $1000 \mathrm{~mm}$, garantindo uma alimentação fácil. Nesse projeto, a vedação da entrada seria feita com uma placa articulada logo no início do sistema de moagem, como visto na Figura 1 b. A placa não reduz em grande quantidade o espaço livre para o fluxo de vidro, mas é de difícil manutenção, e deve ser feita de modo a se fechar com rapidez, por se encontrar muito próxima aos martelos. 

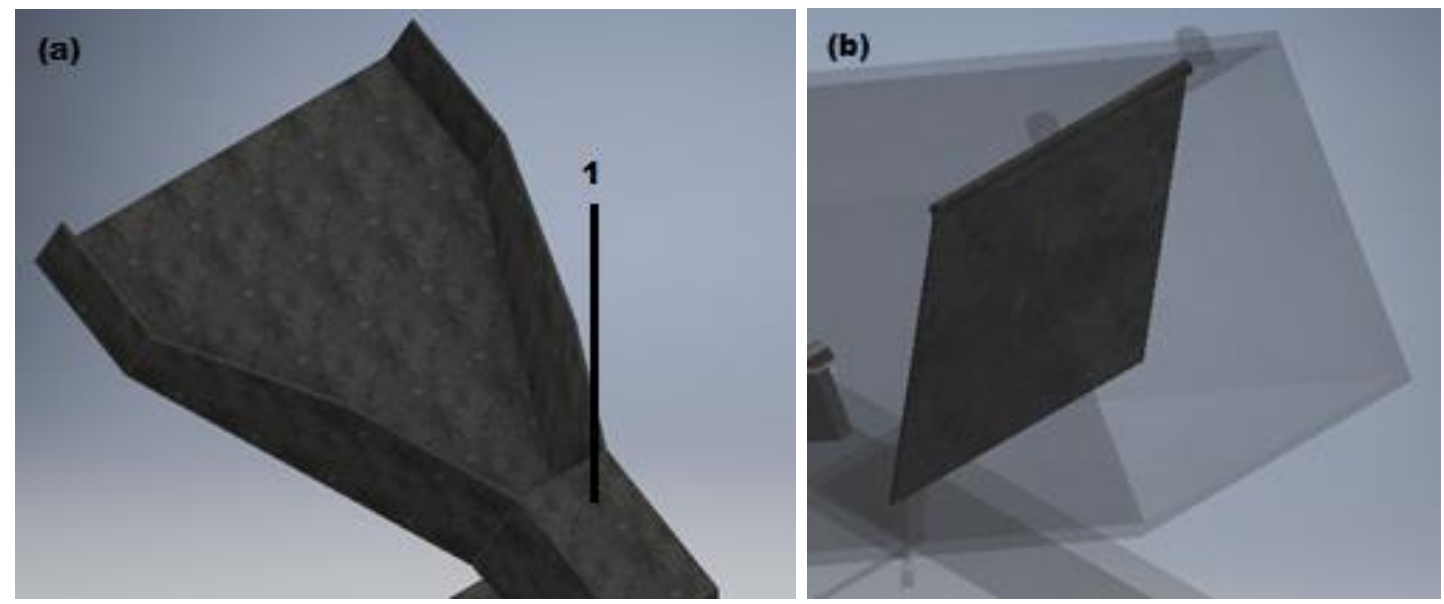

FIGURA 1. (a) Mecanismo de extensão da entrada e (b) detalhe em 1, apresentando o sistema de vedação

O projeto final, por sua vez, foi feito com um sistema tubular, semelhante a uma chaminé. Um cano de diâmetro adequado em desuso foi doado por funcionários da universidade, e com o corte e soldagem do mesmo, foi possível adaptá-lo a máquina.

O sistema está representado na Figura 2. O componente é produzido de material ferroso, não foi possível identifica-lo, tal fator não é de grande influência, pois o canal de entrada não necessita de grande resistência mecânica. $\mathrm{O}$ peso do acessório é de aproximadamente $20 \mathrm{~kg}$. O detalhe em (a) na Figura aponta o novo sistema de vedação, apresentado como um material diferente da entrada para facilitar sua visualização.

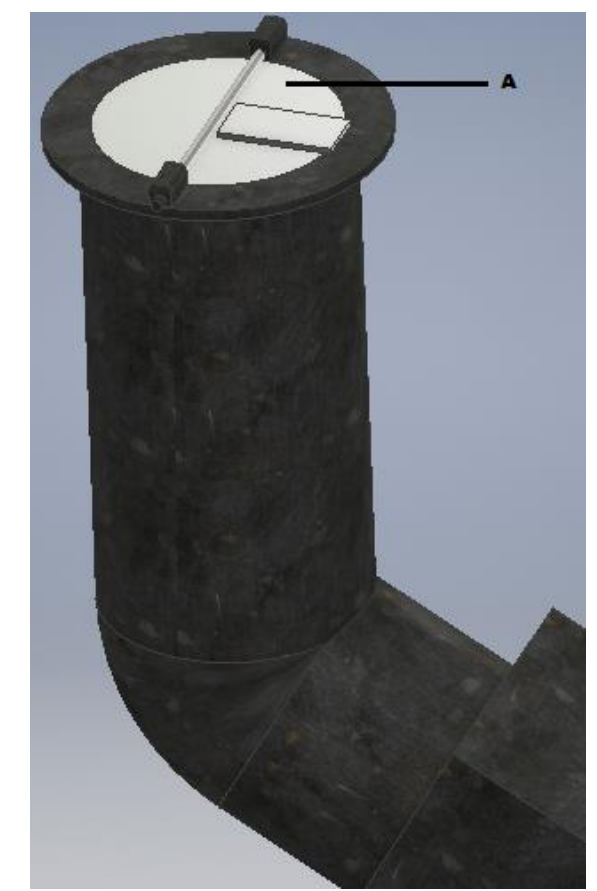

FIGURA 2. Entrada do projeto final 
O sistema funciona por um mecanismo de borboleta, com rotação livre, articulado no centro da placa circular. Um dos lados da chapa deve ser empurrado levemente para realizar a abertura do sistema. No outro lado, foi soldada uma pequena chapa de aço servindo como contrapeso e batente, realizando o fechamento automático do sistema. A vedação obtida por este método é melhor pois o mesmo se localiza mais distante da câmara de moagem, dispondo de maior tempo para fechar-se. Por outro lado, o novo sistema limita o fluxo de material, reduzindo a dimensão real da entrada a metade da chapa circular, de aproximadamente 250 mm de diâmetro.

Comparando os dois projetos, percebe-se inicialmente uma perda de produtividade. Na versão inicial, a alimentação era limitada pelas dimensões da entrada da câmara de moagem, pois as dimensões da calha eram bastante superiores. No projeto final, a vazão de material é limitada pelas dimensões da borboleta, e sua velocidade é reduzida pela necessidade de abri-la. Tais considerações não levam em conta a capacidade do sistema de moagem de processar o material, porém percebe-se que tal capacidade é superior a velocidade máxima de alimentação possível para o projeto final.

Por outro lado, na análise do CG, foi identificada uma aproximação em cerca de $150 \mathrm{~mm}$ na direção horizontal paralela ao canal de alimentação do centro da mesa no novo projeto. Ou seja, há um aumento considerável da estabilidade e diminuição da tensão causada pelo componente nos pontos de apoio. Na direção horizontal perpendicular ao canal de alimentação, o CG se aproxima cerca de $20 \mathrm{~mm}$ do centro da mesa, sendo uma variação razoavelmente positiva, porém a direção de maior interesse para o tombamento é a paralela, por corresponder à parte mais estreita da base. Na direção vertical, o CG foi elevado em cerca de $10 \mathrm{~mm}$, devido a distribuição de massa do tubo. Porém a alteração não é crítica. O desconhecimento do material do componente doado foi compensado pela aproximação do mesmo como sendo produzido pela mesma chapa da calha, elevando seu peso. Por isso, os valores obtidos no cálculo de CG são conservativos.

O peso da máquina com o novo sistema é inferior a $100 \mathrm{~kg}$, e foi reduzido em 50 quilos em relação ao original. A redução facilitou a soldagem do tudo na entrada da câmara de moagem. Além disso, torna a máquina mais robusta e mais fácil de ser transportada.

\subsection{Sistema de moagem}

O sistema de moagem projetado inicialmente consiste em um corpo de seção quadrada, com uma região de entrada e uma região onde se encontram quadro martelos dispostos em distâncias iguais, defasados em 90 graus entre si. Os martelos são acoplados a um eixo, cuja articulação é feita por rolamentos, e conectado, por um acoplamento, ao motor, responsável por acionar o sistema.

A Figura 3 apresenta os elementos descritos. O projeto inicial previa o uso de um motor monofásico de potência $1 \mathrm{HP}$ e 4 polos. A conexão ao eixo seria feita com um acoplamento flexível elastomérico, permitindo alguma angulação. OS rolamentos seriam fixados por mancais modelo F205. Os martelos seriam acoplados ao eixo por peças vazadas, com furos do diâmetro do eixo, e acopladas ao mesmo por chavetas. A distância mínima entre os martelos e a parede da máquina estipulada era de aproximadamente $5 \mathrm{~mm}$. 


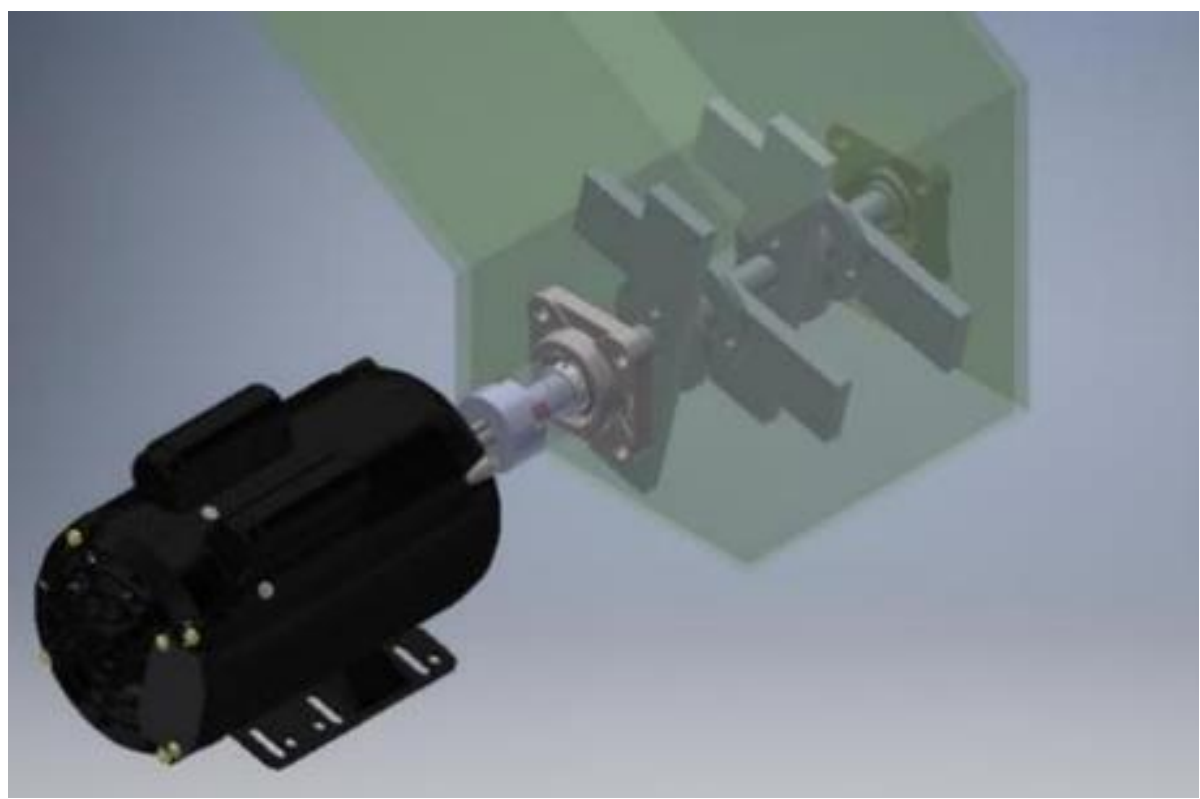

FIGURA 3. Sistema de moagem.

Para a saída, foi planejada a inclusão de uma peneira curvada, objetivando manter-se a uma distância máxima de $5 \mathrm{~mm}$ durante qualquer ponto do percurso. A abertura da peneira seria de aproximadamente 1 $\mathrm{cm}^{2}$.

O produto obtido, nesse conjunto funcional, se aproximou bastante do projetado. Os componentes utilizados foram os mesmos, salvo pela substituição do acoplamento por um tipo cruzeta. Para compensar tal distribuição, tomou-se o devido cuidado na instalação do motor, garantindo a ausência de desalinhamento. Os testes conduzidos comprovaram a viabilidade do acoplamento utilizado. A segurança dos operadores no funcionamento do motor foi providenciada com o uso de uma chave magnética, capaz de desligar automaticamente se houver superaquecimento ou sobrecarga do equipamento, as partes móveis do eixo também foram protegidas com placas metálicas.

Quanto à peneira, devido a dificuldade de se produzir a mesma como planejado, foi construído um acessório substituto a ser usado durante a fase de testes. A nova peneira consistiu em um quadro metálico com as dimensões internas correspondentes às dimensões da saída da máquina. A as paredes internas do elemento são ligadas por barras de aço de cerca de $10 \mathrm{~mm}$ de espessura, dispostas paralelamente a uma distância de cerca de $10 \mathrm{~mm}$ entre si. A peneira é acoplada de moto que as barras estejam perpendiculares à direção de rotação dos martelos. Como o desempenho da máquina nos testes foi satisfatório, optou-se por manter esse acessório como permanente, descartando o projeto anterior. O novo sistema, porém, não confere um controle tão bom quanto à granulometria do vidro moído, mas esse aspecto, segundo os clientes, não afeta na venda do material.

\subsection{Saída}

O projeto original da saída consistia em uma mesa feita de aço, sustentada por quatro pés em formato de L, fabricados em barras também de aço. A mesa possuía as dimensões de 1000x800 mm, e a altura de aproximadamente um metro. Devido a esbeltez dos pés, também seriam adicionadas barras conectando-os em sua parte inferior, visando evitar a abertura dos mesmos com o tempo. A base, em conjunto com a estrutura da câmara de moagem, pode ser vista na Figura 4, já construídas. A vedação da saída seria feita com um material têxtil resistente formando um tubo flexível entre a peneira e o recipiente. 


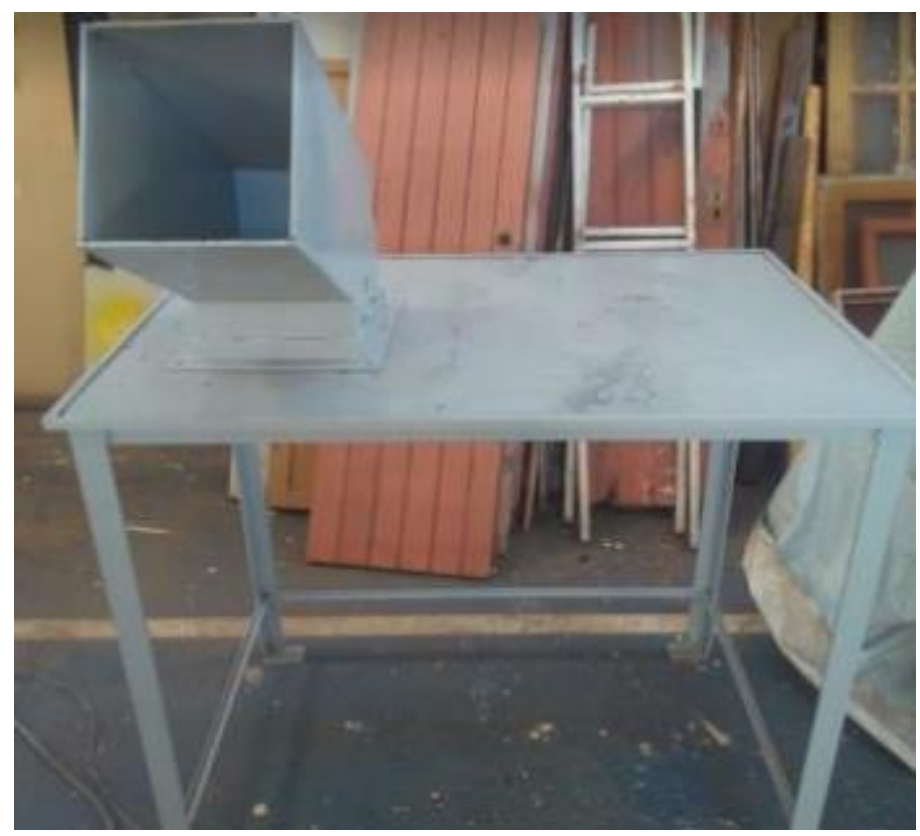

FIGURA 4. Base e estrutura da câmara de moagem.

A principal alteração neste aspecto foi referente ao comprimento dos pés. Embora a altura original possuísse um bom espaço para a acomodação dos recipientes de armazenamento de vidro, suas dimensões eram exageradas. A alimentação da máquina seria demasiado complicada com a altura do projeto original, cerca de dois metros. Por isso, foram retirados cinquenta centímetros dos pés, cerca de metade de seu comprimento. A altura reduzida facilitou a alimentação e dispensou a inclusão das barras de suporte. Além disso, o CG é aproximado do solo, afetando positivamente a estabilidade da estrutura.

A FIGURA 5 apresenta a parte inferior da base, como descrita, logo após o corte dos pés. Eles ainda foram preparados e pequenas chapas de metal foram soldadas a cada um, visando maior estabilidade. É possível ver ainda a peneira mencionada anteriormente. 


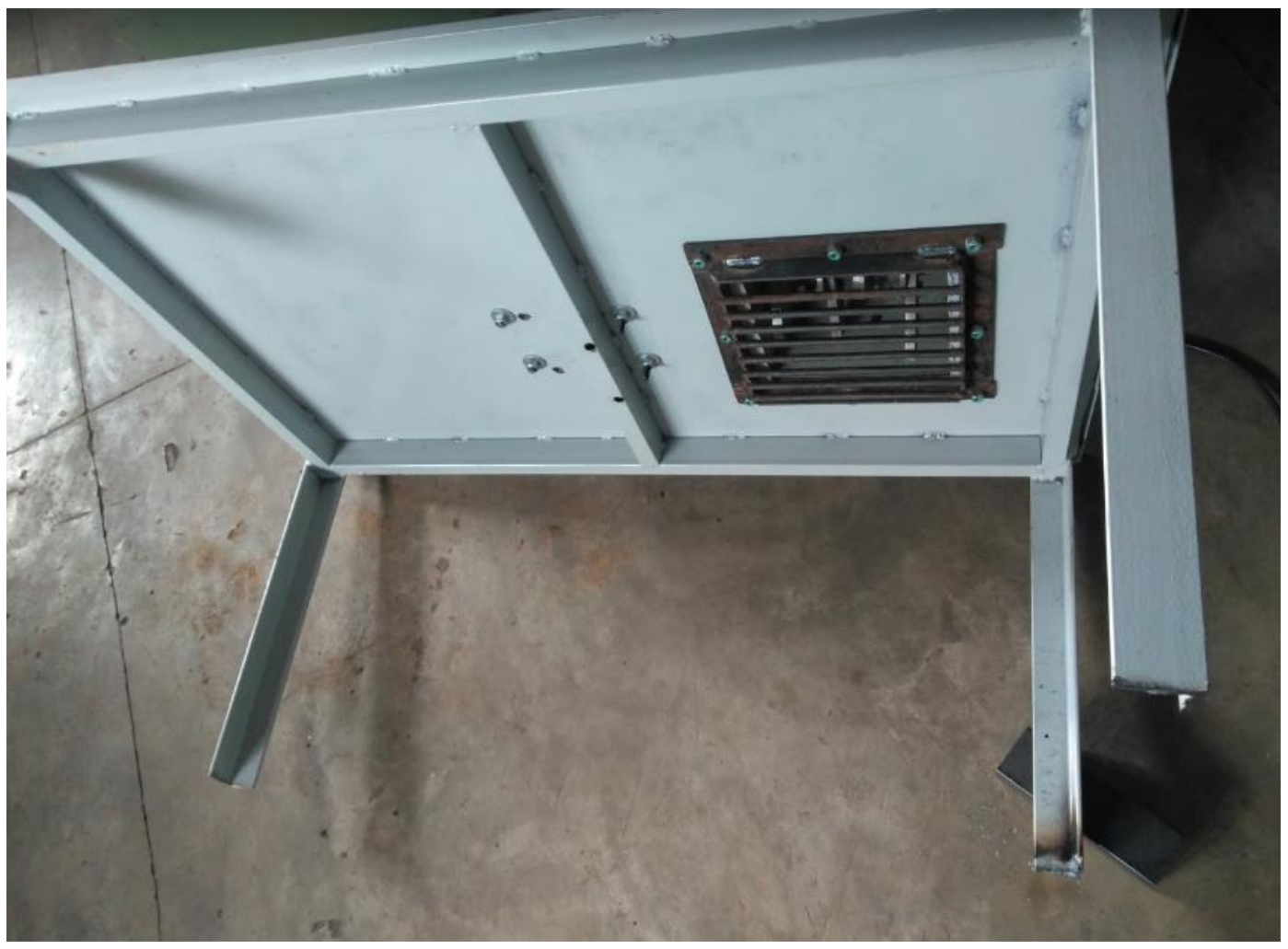

FIGURA 5. Parte inferior da base.

Um pedaço de raspa, tecido bastante resistente e barato, foi utilizado na vedação. Ele foi preso utilizando-se dos mesmos parafusos responsáveis pela fixação da peneira e do conjunto de moagem na base. A vedação ainda apresenta deficiências, pois permite a passagem de algumas partículas, que se acumulam ao redor da saída.

Abaixo da máquina ainda há um espaço considerável para a colocação de recipientes. Considerando-se a densidade razoável do vidro, os mesmos não podem ser muito grandes, ainda que houvesse espaço, pois seu transporte seria impossível com os recursos disponíveis na ASCAS.

\section{CONCLUSÕES}

O processo de projeto não é linear, e não possui um objetivo claro, cabendo ao projetista defini-lo e alterá-lo se necessário. Durante o projeto da trituradora de vidro, tal asserção ficou clara. Foram descobertas várias formas de se alcançar o objetivo inicial de triturar o vidro, e, mesmo dentro do mecanismo escolhido, diversas minúcias permitem escolher vários caminhos para se definir uma máquina funcional.

O projeto inicial possuía plena capacidade de realizar a cominuição do material, todavia durante o processo de realização do mesmo, percebeu-se sua inviabilidade perante os recursos e limitações peculiares ao mecanismo em questão. Ao fim, obteve-se uma máquina semelhante da original em alguns pontos, porém diferente em vários outros. Mas ambas são capazes de realizar a tarefa proposta, embora a segunda seja mais adaptada a esta situação.

O primeiro modelo possuía uma alta produtividade, uma segurança aceitável e um peso elevado, embora ainda apto para transporte. Também se apresentou estável se operada corretamente, mas sua distribuição de peso tende a facilitar o tombamento. Seu sistema de entrada, embora eficiente, era pesado e possui uma massa distribuída de forma indesejável. O sistema de moagem foi projetado de forma a garantir 
uma cominuição controlada do material, quanto ao fluxo e granulometria. A base era suficientemente estável e rígida, porém bastante esbelta, exigindo reforços em sua parte inferior, além de tornar a máquina alta.

O modelo final, por sua vez, comprometeu-se na questão de produtividade, porém se mostrou mais seguro e estável, além de leve. O sistema de entrada forneceu maior segurança ao operador, com uma vedação capaz de conter uma maior quantidade de partículas. Além disso, o canal teve um peso muito menor e melhor distribuído, quase impossibilitando o tombamento em qualquer condição de operação. O sistema de moagem entregou um particulado com granulometria menos controlada, porém adequado às necessidades da associação. A base apresentou maior estabilidade sem a necessidade de reforços, com espaço suficiente para acomodar recipientes coletores do vidro e permitir a alimentação confortável por parte do operador. A vedação ainda exige um processo de otimização para se tornar devidamente adequada.

Nenhum dos projetos foi ótimo, havendo a possibilidade inclusive da combinação de aspectos de ambos na produção de uma versão definitivamente melhor. Foi possível perceber a necessidade de adequar o projeto teórico ao ambiente e à situação no qual o equipamento será utilizado e produzido.

A avaliação foi realizada de modo satisfatório, fornecendo uma visão geral das diferenças entre os equipamentos comparados. As alterações feitas representaram vantagens e desvantagens em relação ao projeto original, e foi importante conhecer as mesmas, possibilitando, futuramente, aplicar mudanças visando sanar os aspectos negativos do modelo em funcionamento.

\section{REFERÊNCIAS}

\section{- Periódicos:}

FERRARI, M. V. D. et al. O POTENCIAL DA CADEIA DE RESÍDUOS DE VIDRO DE EMBALAGEM NO DISTRITO FEDERAL. In: Forum Internacional de Resíduos Sólidos. Anais. 2018.

FRIEDRICH, I. Factors affecting the particle reduction process in hammer mill. Die Muhlem, n. 48, p. 648-651, 1959.

JINDAL, V. K.; AUSTIN, Leonard G. The kinetics of hammer milling of maize. Powder Technology, v. 14, n. 1, p. 35-39, 1976.

YANCEY, Neal; WRIGHT, Christopher T.; WESTOVER, Tyler L. Optimizing hammer mill performance through screen selection and hammer design. Biofuels, 4:85-94, 2013.

- Trabalhos publicados em anais de evento:

PASSOS et al. PROJETO DA ESTRUTURA FÍSICA DE UMA TRITURADORA DE VIDRO. In: XVIII CONGRESSO NACIONAL DE ENGENHARIA MECâNICA E INDUSTRIAL, 2018. XVIII Congresso Nacional de Engenharia Mecânica e Industrial, 2018.

- Livros e outras monografias:

ABREU, J. C.; BARBOSA, V. R. Cooperativismo popular e redes solidárias. Monitoramento do processo de gestão da Associação dos Catadores de Materiais Recicláveis de São João del-Rei ASCAS. São Paulo: All Print, 2007. p. 181-200.

CALLISTER, W. D.; RETHWISCH, D. G. Ciência e Engenharia dos Materiais, uma introdução. LTC, 2016.

ANDRADE, J. V. M.; CHIRIBOGA, Andrea E. O. Diseño y construcción de un molino de martillos triturador de $15 \mathrm{qq} / \mathrm{h}$ de mineral pétreo para producir biofertilizantes. Trabalho de Conclusão de Curso. Ago. 2018

FILHO, E. R. et al. Projeto do Produto. Rio de Janeiro: Elsevier: ABEPRO, 2011. 

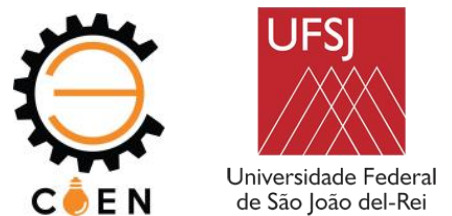

KOCH, K., Hammermills and Roller mills. Kansas State University Agricultural Experiment Station and Cooperative Extension Service. Kansas State University, mai. 2002

MEDINA, M., In: Chen, et al.: Membership Based Organizations of the Poor. Waste Picker Cooperatives in Devloping Countries. Routlegde Studies in Development Economics, London, UK, 106 - 108 p., 2007.

NORTON, R. L. Projeto de máquinas, uma abordagem integrada. Bookman, $5^{\mathrm{a}}$ Ed. 2013.

RAHAMAN, Mohamed N. Ceramic processing and sintering. CRC press, 2003.

SHIGLEY, J. E.; et al. Projeto de Engenharia Mecânica. Bookman, 7.ed., 2005.

- Páginas de internet:

ASSOCIAÇÃO TÉCNICA BRASILEIRA DAS INDÚSTRIAS AUTOMÁTICAS DE VIDRO (ABIVIDRO). Benefícios da reciclagem do vidro. Disponível em: <http://www.abividro.org.br/reciclagem-abividro/benefcios-da-reciclagem-do-vidro>. Acesso em 09 jun. 2019.

MICHAUD, L. F. HAMMER MILL GRINDER, 911 Metallurgist. 25 feb. 2016. Disponível em: <https://www.911metallurgist.com/blog/hammer-mill-working-principle>. Acesso em: 09 jul. 2019.

SYSTEMATIC EVALUATION OF CHANGES ON THE DESIGN OF A GLASS GRINDER (deixar uma linha em branco - Times New Roman, tamanho 11)

Primeiro Autor ${ }^{(1)}$ (e-mail), Segundo Autor ${ }^{(2)}$ (e-mail), $\cdots$, No máximo quatro Autores ${ }^{(n)}$ (e-mail) (Times New Roman, tamanho 11, centralizado)

(deixar uma linha em branco - Times New Roman, tamanho 11)

(1) Instituição (SIGLA) - Departamento - Endereço (Times New Roman, tamanho 9, centralizado - ocupar apenas uma linha)

(2) Instituição (SIGLA) - Departamento - Endereço (Times New Roman, tamanho 9, centralizado - ocupar apenas uma linha)

(n) Instituição (SIGLA) - Departamento - Endereço (Times New Roman, tamanho 9, centralizado - ocupar apenas uma linha) (deixar uma linha em branco - Times New Roman, tamanho 11)

ABSTRACT: After identifying a high demand in the city of São João del-Rei, Minas Gerais, and aiming to help the city's Association of Waste Pickers with a new source of income, a design of a glass grinder was proposed, based on product design techniques and Social Technology. The machine was developed by students and teachers from of the Federal University of São João del-rei's Mechanical Engineering course. This process resulted in a simple equipment, capable of managing glass waste, turning it into small and easily handled pieces safely and efficiently. To develop a trustworthy, environmentally friendly, economically viable and easily maintained equipment, correctly determining the machine's operating conditions, as well as its adequate sizing is essential. The design was inspired on simple mechanisms, basing its working principle on the impact between hammers and the material being grinded, common in hammer mills. During its construction, some changes were made in the original project's scope, due to unpredicted obstacles. The new design showed satisfactory characteristics in tests related do its original goals and capacity of solving the identified obstacles. Considering these observations, the present work aims to evaluate the machine as a whole, comparing the original, theoretical project and the built and delivered version, defining the influence of the aforementioned unforeseen changes made during its construction.

(deixar uma linha em branco - Times New Roman, tamanho 11)

KEYWORDS: mechanical design, hammer mill, glass, recycling, pickers. 